\title{
O papel da Mediação Psicopedagógica nos Primeiros Contatos com a Leitura e a Escrita
}

\author{
Maria Ines Corte Vitoria*, Milena Ramos**, Claus Dieter Stobaus*, Juan José Moriño Mosquera*** \\ *Faculdade de Educação, Pontifícia Universidade Católica do Rio Grande do Sul. **Revisão, Sistema Fecomércio-RS. \\ ***Facultade de Letras, Pontifícia Universidade Católica do Rio Grande do Sul. Brasil.
}

\begin{abstract}
Resumo
A pesquisa tem como objetivo analisar as boas práticas pedagógicas de leitura e escrita num curso de Graduação, a partir das contribuições da psicopedagogia. A coleta de dados foi feita com alunos do curso de Pedagogia da PUCRS/Brasil. Os dados resultaram nas categorias: 1 O papel da Mediação Psicopedagógica nos Primeiros Contatos com a Leitura e a Escrita; 2 - Formação da Cultura Leitora e de Escrita; 3- Sentimentos Despertados pela Leitura e Escrita no Curso investigado; 4 - Leitura e Escrita nos Âmbitos Pessoal e Profissional. 5 - As contribuições que a prática psicopedagógica representa para a formação da pessoa do leitor/escritor.
\end{abstract}

Palavras-chave: Psicopedagogia, Leitura, Escrita, Formação de professores.

\section{A psicopedagogia na formação de professores}

A presente pesquisa - em fase de desenvolvimento busca caracterizar a leitura e a escrita em contextos de formação de professores, numa perspectiva de integrar as contribuições da psicopedagogia nos cursos de Graduação. Nesse sentido, analisando as práticas pedagógicas que favorecem o desenvolvimento da escrita e da leitura em tal contexto, é inevitável que se reflita numa abordagem que compreende a interdisciplinaridade como fundamento sobre o qual as ações devem ser desenvolvidas, neste caso específico, pedagogia e psicopedagogia atuando de forma complementária e potencializadora na formação de professores. A presente pesquisa se ampara nos princípios da pesquisa qualitativa, contando com dados coletados através de entrevistas aplicadas a professores de Graduação. Optouse por trabalhar com essas técnicas de caráter eminentemente qualitativo, pois elas permitem buscar elementos que caracterizam os processos de escrita e leitura na formação de professores, contando com um trabalho conjunto entre pedagogia e psicopedagogia. Nesse sentido, se espera chegar a práticaspedagógicas que contribuam para a formação de professores, refletindo sobre ações que possam fortalecer aformação de professores, oferecendo mais consistência e preparo para atuação profissional. Sendo assim, fica clara a necessidade de ser repensado os processos de ensino a partir da relação que estabelece entre diferentes áreas de conhecimento. A capacidade aprendizado de um sujeito, adulto ou criança, depende dos conhecimentos variados que ele precisa desenvolver para que as habilidades cognitivas e socioemocionais se desenvolvam de forma integrada e significativa. Nessa perspectiva, faz-se importante ressaltar que outros aspectos emergem como necessários para que o estudo em questão dê conta da qualificação da formação de professores, mais especificamente neste estudo uma formação que compreende a indissociabilidade entre pedagogia e psicopedagogia. São eles: O que o aluno não sabe quando sente dificuldade de organizar e desenvolver as próprias idéias? Qual o entendimento do aluno sobre organização e desenvolvimento de idéias? Que aspectos o levam a não aprender? Que aspectos limitam as aprendizagens num curso de Graduação? Estas e outras indagações necessitam de dois campos de conhecimento para serem respondidas: a pedagogia e a psicopedagogia. Nesta perspectiva, tal estudo assume como referência diversos processos educativos de Formação de Professores no contexto investigado. Marcelo Garcia (1999), em seu texto Formação de Professores, traz muitas contribuições para o conceito de formação, indicando que esse é um conceito "susceptível de múltiplas perspectivas” (p.19). Nesse texto, preferencialmente, apresenta conceitos de formação relacionados ao desenvolvimento pessoal. De Zabalza, Marcelo Garcia (1999, p.19) traz que formação é “o processo de desenvolvimento que o sujeito humano percorre até atingir um estado de plenitude pessoal".

\section{Formação da Cultura Leitora e de Escrita}

Reafirmamos a docência como uma atividade interdisciplinar, complexa, uma produção não-material que exige um preparo prévio de processos e procedimentos de ensino e aprendizagem. E esses processos são possíveis quando aprofundamos as relações com a pesquisa em parceria, lendo a realidade e ocupando os espaços de contradição.A alfabetização tem merecido inúmeras investigações nas últimas décadas. Não obstante esses estudos, os censos e dados estatísticos apontam índices elevados de repetência e evasão nas séries iniciais do Ensino Fundamental. Dados oriundos de avaliações oficiais, tais como Prova Brasil; Exame Nacional Ensino Médio, apontam os baixos índices de desempenho dos alunos, especialmente no que se refere à leitura e compreensão de diferentes textos, como um dos desafios ainda não superados pela educação brasileira. Cabe destacar que o Brasil atravessou o séc. XX carregando dados negativos que o colocam como um dos países com pior desempenho educacional da América Latina. E iniciamos o séc. XXI com um contingente de

Correspondência: Maria Ines Corte Vitoria: mvitoria@pucrs.br - Milena Ramos: milena.ramos@acad.pucrs.br - Claus Dieter Stobaus:

stobaus@pucrs.br - Juan José Moriño Mosquera: juan.mosquera@pucrs.br

Selección y peer-review bajo responsabilidad del Grupo de Investigación G000422-GIPDAE, Universidade da Coruña, España. 
15 milhões de jovens e adultos analfabetos absolutos (IBGE - Censo demográfico de 2000). Acreditamos que há muito que investigar ainda sobre a alfabetização, especialmente sobre o processo de aprendizagem inicial da leitura e da escrita, já que quando se fala em escrita fala-se necessariamente também em leitura.

Trazemos a contribuição de Cristofoli (2002), quando a autora fala sobre sua investigação que lhe permitiu aprofundar algumas questões prévias de seu repertório e, ao mesmo tempo, verificar e elaborar outras possibilidades e novas indagações.

Um estudo, por mais focado que tente se instalar será sempre um fragmento da realidade. É apenas parte de um todo. Para Santos (1994) é uma ilustração do conhecimento total. É o olhar da autora instigado pela ótica dos teóricos, Piaget na busca de respostas à temática do estudo, a aprendizagem inicial do ler e escrever.

A escola ensina a ler e a escrever, segmentando a língua escrita em letras, sílabas, palavras e, eventualmente, orações. Os textos, poesias ou contos, quando são oferecidos às crianças, vêm através da leitura do professor e são usados como suporte para a retirada de palavras, que são analisadas, escritas no quadro e copiadas. As crianças costumam nomear as letras pelos valores silábicos iniciais das palavras do alfabeto ilustrado: "ca" do cavalo, "ba" da baleia, "na" do navio. Cinco crianças desse estudo soletravam, dizendo o nome das letras: "pê", "ene", "e", "u", mas em seguida tentavam ler a palavra e apropriar-se do seu significado. Somente uma das crianças manteve-se soletrando, a criança 4, até escrever alfabeticamente, trajetória que acompanhei durante um ano e meio. E, mesmo já estando escrevendo alfabeticamente necessitava soletrar, balbuciava o nome das letras e então lia em voz alta toda a palavra.

O fato de soletrar é uma das prováveis causas que fizeram com que $\mathrm{C} 4$ permanecesse tanto tempo num mesmo nível de leitura e escrita, nível dois, em que escrevia com quatro ou cinco letras, qualquer palavra, variando os grafismos, e soletrava, às vezes, tentando atribuir um significado, inventando uma palavra para a soletração que fazia.

Um dos resultados desta prática do uso do alfabeto ilustrado aparece na inusitada leitura que $\mathrm{C} 4$ faz do poema "Era uma casa" no qual para cada letra, dizia o nome da palavra que aparecia no alfabeto: "estrela", "rato", "a", "uva", "meia", ...

Ferreiro (2002, p.58), tecendo críticas a debates pedagógicos ultrapassados, afirma que foi preciso mostrar que os copistas não são produtores de texto, destroçar os rituais de recitação das famílias silábicas, ridicularizar os enunciados escolares... e deixar entrar no grande cenário e de pleno direito dois grandes ausentes da formulação tradicional: a língua escrita e a criança que pensa. A soletração parecia constituir-se num obstáculo, para que $\mathrm{C} 4$ avançasse, tanto no processo de leitura como na escrita. Entretanto, C2, que não realizou em nenhum momento a soletração, foi a criança que avançou com mais rapidez nos níveis de leitura e de escrita (a única palavra que C2 soletrou foi "criança" quando não conseguiu ler). Da mesma forma, C3, que soletrou só no primeiro encontro, mas que também buscava atribuir um significado ao que era lido.

Os avanços cognitivos verificados ao longo do processo no estudo de Cristofoli (2002) mostraram que a escrita em alguns encontros precedia a leitura, provavelmente, por ser priorizada no processo de alfabetização, em detrimento da leitura, mas isso só ocorria em um curto espaço de tempo.

$\mathrm{O}$ encontro seguinte também já mostrava um avanço da leitura. Embora a leitura ocupe um pequeno espaço no cenário pedagógico, ela desenvolve-se, pois está vinculada à escrita. A aprendizagem e o desenvolvimento cognitivo de cada um dos processos que, na maioria das vezes são trabalhados, estão atrelados às possibilidades de experiências com a língua escrita, com o ler e o escrever. Aprende-se a ler, lendo, aprende-se a escrever, escrevendo.

Os objetivos da escrita, na escola, alteram e limitam as noções das funções da escrita. E retoma-se a questão: o ato isolado de decifrado não se constitui como um ato completo de leitura; a decifração, sem busca de significado, retarda o desenvolvimento da leitura e da escrita, como observou-se com C4.

\section{Sentimentos Despertados pela Leitura e Escrita no Curso investigado}

Nesta questão, buscamos focar, à luz da psicopedagogia, os sentimentos dos alunos enquanto leem e escrevem, dando ênfase, então, a pessoa do leitor/escritor no curso investigado, buscando entender o que desperta o bem-estar no aluno que lê e escreve e o que precisa ser aprimorado para o alcance disso.

[...] Utilizo a leitura e a escrita na graduação, para anotações pessoais do que acho mais relevante das aulas. As anotações, as vezes, são reflexões ou até mesmo sentimentos. [...] também por algum pensamento aleatório que possa ter surgido durante a aula. Quanto a leitura, não gosto de realizar em sala de aula, prefiro um ambiente que me proporcione mais solidão. (S1)

Ler e escrever, atos tão naturais de quem possui a cultura das letras, hábito que eu pratico como formula de reflexão e exteriorização de tudo que me aflige e fascina. [...] mas a leitura e escrita reflexiva é algo que deveria ser mais utilizado nas escolas. (S12)

[...]O curso de Pedagogia exige bastante leituras e muitas vezes comentários críticos sobre a leitura feita [...]. Gosto muito de ler. [...]. Também acho inviável um educador que não goste de ler, como incentivará as crianças e os jovens se ele próprio não lê?

Assim, a percepção do(a) aluno(a) de Pedagogia sobre a importância do gosto pela leitura por parte do professor é algo louvável, pois denota que o/a graduando(a) tem convicção do quanto o professor leitor pode incentivar e influenciar seus alunos.

Conforme Lajolo (1999, p. 108):

A discussão sobre a leitura, principalmente sobre a leitura numa sociedade que pretende democratizar-se, começa dizendo que os profissionais mais diretamente responsáveis pela iniciação na leitura devem ser bons leitores. Um professor precisa gostar de ler, precisa ler muito, precisa envolver-se com o que lê. 
Percebemos, nesta categoria que foca os sentimentos despertados no leitor/escritor na Graduação, respostas bem diferenciadas, como a preferência da leitura em solidão, as escritas em aula de sentimentos e pensamentos despertados nas aulas, para outros a leitura como algo natural e tranquilo, por já ser uma pessoa mais acostumada aos textos.

[...]Normalmente temos que ler muitos textos, livros, polígrafos em um curto espaço de tempo e isso dificulta a compreensão dos mesmos. (S9)

A liberdade de escrever em nossos trabalhos postados no moodle e nos trabalhos entregues em mãos é o nosso maior exercício de ler e escrever aqui na graduação.

Poder vivenciar a teoria e a prática ao mesmo instante é bastante esclarecedor e motivador assim como nos fazem sentir segurança na construção de novos conhecimentos. Descobrir que se é capaz e que a pessoa (professora) acredita e aposta em sua capacidade é muito prazeroso e significativo. A escrita e a leitura é constante e necessária. Como aluna me sinto valorizada e não tem nada melhor que isto. (S4)

Aqui destacamos os sentimentos do sujeito participante da pesquisa em relação á professora da disciplina, a comparação da teoria com a prática proporcionada pela professora referentes à escrita e à leitura. Acreditamos, ainda, que é importante salientarmos quão positivas são as palavras utilizadas por este sujeito para explicitar seus sentimentos em relação à utilização da leitura e da escrita na Graduação, especificamente na disciplina que comentamos: esclarecedor, motivador, segurança, descobrir, construção, prazeroso, significativo, valorizada. Todas essas palavras carregam consigo uma atmosfera de coisas boas, positivas, de sentimentos importantes que contribuem para o bem-estar do aluno e, com certeza, propiciam um ensino de maior qualidade $\mathrm{e}$ melhores resultados.

Nesse sentido, conforme Mosquera e Stobäus (apud Enricone, 2006, p. 108):

Acreditamos que, nos ambientes escolares, é necessário desenvolver aspectos de autoimagem e autoestima mais positivos e realistas, porque no sistema educativo se interage de maneira intensiva, para o desenvolvimento da própria pessoa e suas dimensões socioculturais.

Salientamos que essas colocações atribuídas às aulas e à professora confirmam e corroboram com as descrições que anteriormente fizemos sobre o que observamos durante o Estágio de Docência e acompanhamento das turmas da disciplina, o que denota que os alunos também estão atentos e sequiosos por aulas e professores que contribuam para além da transmissão de conteúdos, aplicação de provas e conclusão de mais uma disciplina ao final do semestre. Buscamos compreender a admiração pelas aulas da professora por parte dos alunos, e pelo entusiasmo com que conduz sua disciplina, e concluímos que, por todas essas características, a professora também contagia os alunos com seu exemplo. Eles conseguem perceber sua paixão pelos livros, pela escrita e reconhecem a habilidade da discente no que faz, de modo que ela passa a ser um exemplo de sucesso a ser seguido. E, mesmo a maioria já estando no início da fase adulta, outros já em seus meados, bons exemplos entusiasmados são contagiantes, bem como acreditamos que atuem como um bálsamo, que facilita e ameniza as correrias do dia a dia, de trabalho em turno integral, mais a universidade à noite, configurando o terceiro turno do dia, como já mencionamos, mostrando que vale a pena estar ali para adquirir novos conhecimentos.

Utilizo a escrita e a leitura sempre. Nas letras as leituras obrigatórias acabam por fazer parte do dia a dia. (S10) [...]A Puc deveria dar um curso de LEITURA DINÂMICA E MEMORIZAÇÃO para nos ajudar a ler e interpretar o mais rápido possível [...] Seria uma boa para todos, pois escreveríamos melhor, se compreendêssemos melhor os textos, dentro desse espaço esmagador de cada semestre. (S5)

Por fim, nesta última resposta, verificamos o anseio por conseguir ler, memorizar e interpretar "o mais rápido possível", evidenciando o sentimento de que há muita demanda e pouco tempo para dar conta das leituras e trabalhos da universidade, bem como mostra que os próprios alunos percebem que precisam escrever e compreender melhor os textos. Para Lajolo (1999, p. 105),: A atividade de leitura, que, em suas origens, era individual e reflexiva (em oposição ao caráter coletivo, volátil e irrecuperável da oralidade de poetas $e$ contadores de histórias), transformou-se hoje em consumo rápido do texto, em leitura dinâmica que, para ser lucrativa, tem de envelhecer depressa, gerando constantemente a necessidade de novos textos.

Então, acreditamos que cabe aos professores da Graduação, que lidam com a formação de professores, capacitar os discentes para a leitura dinâmica, por uma questão de necessidade profissional, inclusive, mas que, levem igualmente em conta as contribuições da psicopedagogia para que a formação do leitor consciente, atento e que consiga deleitar-se com um texto.

\section{As contribuições que a prática psicopedagógica pode trazer para a formação da pessoa do leitor/escritor nos cursos de Graduação.}

Pode-se dizer, na perspectiva de Zabalza (2004), que escrever diários de aula exige também uma organização daquilo que se quer registrar. Pelo fato de o registro exigir aspectos significativos sobre sua prática, os professores talvez também se deparem com dificuldades, pois, para alguns, pode ser uma ação remota escrever sobre sua atuação docente: tanto pela quase inexistência de produção intelectual, quanto pelos registros no formato de diários de aula ser algo recente no contexto educacional e, especialmente por este motivo, exige por parte dos docentes tempo e dedicação, tanto pelo fato de registrar seus sentimentos e idéias, como por permitir um distanciamento necessário para a reflexão sobre sua prática docente, com o objetivo de ressignificá-la e redimensioná-la constantemente.

Se a academia não faz desta uma realidade presente ao longo do curso, possivelmente essa reflexão não acontece e não se torna uma prática permanente. Para Contreras (2002, p. 108) "esta reflexão na ação profissional não é necessariamente algo pontual e rápido. Estaria, mais precisamente, em relação com os limites de tempo que a própria prática impõe". Diante da realidade de inúmeras demandas que se tem no cotidiano docente, torna-se 
imprescindível um tempo para reflexão, do contrário fica a prática pela prática.

Conforme Zabalza (2004, p. 11), os Diários de Aula servem "como um recurso formativo no âmbito da formação permanente dos docentes e profissionais da educação" e em seguida ainda afirma que "esse é o itinerário que muitos professores são capazes de seguir por meio da atividade narrativa e reflexiva que os diários proporcionam".

Nesses registros, são relatados os sentimentos em relação a ele próprio diante do vivido e em relação aos alunos e à prática da sala de aula. Por isso, na perspectiva de Zabalza (2004, p. 17) "os diários permitem aos professores revisar elementos de seu mundo pessoal que frequentemente permanecem ocultos à sua própria percepção enquanto está envolvido nas ações cotidianas de trabalho". Reforçamos a possibilidade da escrita docente no intuito de efetivamente contribuir para a reflexão e aprimoramento pedagógico. Nos valemos das palavras de Bolzan (2009) que colocar as ideias no papel, favorece o professor a se conscientizar $e$ compreender sobre temas ou questões relativas ao seu fazer e auxilia o esclarecimento e discussão com outros sobre os temas em questão, indicando que pedagogia e psicopedagogia são campos de conhecimento com estreita relação e que devem andar juntos na formação de professores.

Ao registrar, o professor já realiza uma espécie de catarse sobre si mesmo. Ao reler essa escrita, reorganiza seu pensamento e analisa os aspectos relevantes e aquilo que precisa ser eliminado e reconstruído em sua prática na sala de aula. $\mathrm{O}$ registro, no nosso entendimento, tem uma dupla função: ser um espaço de desabafo com o diário e também abre caminhos para posteriores reflexões a partir das retomadas feitas, o que consequentemente auxilia seu aluno na produção escrita. Para Bolzan (2009, p. 17) ao refletir, ele passa a pensar sobre a situação passada, estabelecendo relações com situações futuras de ensino que virá propor e organizar. Esse processo de reflexão crítica, feito individualmente ou em grupo, pode tornar conscientes os modelos teóricos e epistemológicos que se evidenciam na sua atuação profissional e, ao mesmo tempo, favorecer a comparação dos resultados de sua proposta de trabalho com as teorias pedagógicas e epistemológicas mais formalizadas.

Através do registro, o professor vai reunindo inúmeras informações que lhe sejam significativas para rever sua prática com os alunos em sala de aula. $\mathrm{O}$ fato de escrever, o que contém essa escrita, a forma como escreve e sobre quem é produzida essa escrita traduz exatamente o que faz, como faz, qual seu pensamento sobre cada aluno, sobre a proposta curricular, sobre os valores, e, sobre os princípios de convivência no espaço escolar (HOFFMANN 2008).

O envolvimento do professor em seu trabalho no cotidiano universitário não permite muitas vezes que possa refletir sobre sua ação docente. Nesse sentido, é que se propõe o registro, pois na ótica de Zabalza (2004, p.18) o diário cumpre um papel importante como elemento de expressão de vivências e emoções. Escrever sobre si mesmo traz consigo a realização dos processos [...]: racionaliza-se a vivência ao escrevê-la, reconstrói a experiência, com isso dando a possibilidade de distanciamento e de análise e, no caso de desejá-lo se facilita a possibilidade de socializar a experiência, compartilhando-a com um assessor pessoal ou com o grupo de colegas.

Escrever sobre sua prática, permite ao professor, artesanalmente, ir (re)elaborando e (re)construindo sua ação pedagógica, seus conhecimentos sobre cada um de seus alunos, e, sobretudo, abrir caminhos para a reflexão. O registro é importante porque é uma forma de manter vivo tudo aquilo que a memória por si só não armazenaria com tantos detalhes por um longo período de tempo. Por isso, destaca-se que os professores tem, "através da escrita dos diários de aula, momentos de retomada, de reflexão sobre todos os aspectos subjacentes ao fazer docente e sobre si, afinal, o bem-estar pessoal se reflete automaticamente no bem-estar profissional" (HERBERTZ e VITÓRIA 2010, p. 39). Toda vez que escreve, a escrita está embebida de sensações e sentimentos daquele momento vivido. Na medida em que há o distanciamento, é possível ter outro olhar sobre a mesma escrita.

\section{À guisa de conclusão}

Em geral, as propostas de alfabetização empregadas nos cursos de formação de professores partem do pressuposto de que a criança começa a aprender alguma coisa sobre a escrita a partir de sua exposição sistemática a um determinado método. Esses tendem a se basear na crença de que o importante na alfabetização é codificar sons em letras (para poder escrever) e decodificar letras em sons (para poder ler). Neste sentido, a escrita tende a ser tomada como uma transcrição da oralidade, e sugere a idéia de que para escrever bem é necessário falar bem. Tradicionalmente, a escola alfabetiza tendo a crença de que a escrita espelha a oralidade e, por esta razão, estrutura atividades escolares que objetivam levar as crianças à descoberta de um princípio alfabético, de correspondências regulares entre sons e letras.

A escola não consegue conceber o erro como algo inerente ao processo de aprendizagem. Para Teberosky (1991), é urgente dar outra interpretação às alterações ou dificuldades ortográficas. Numa perspectiva em que a língua escrita é vista como transcrição da oralidade, seu ensino será feito por meio de princípios de memorização e automatização. Por isso, o errar tende a ser visto como uma falha. Para os que trabalham com este tipo de conceito, fica difícil conceber o erro como resultante de um processo de interação, no qual a criança atua sobre a linguagem escrita com a finalidade de apropriar-se dela, processo esse que ocorre desde muito cedo, conforme evidenciaram ferreiro (1991) e Teberosky (1991). Esta abordagem atualmente tem sido bastante difundida, o que não significa, necessariamente, estar sendo implementada. Para Ferreiro (1991), as crianças não são aprendizes passivos, mas, sim, ativos. Para Vygotsky (1999) “a linguagem escrita é uma função lingüística distinta, que difere da linguagem oral tanto pela sua estrutura como pela sua função. Até os seus estágios mais elementares de desenvolvimento exigem um alto nível de abstração". 
Kato (1986) propõe estratégias pedagógicas de duas naturezas para os fatores que concorrem para o sucesso ou insucesso da aprendizagem da leitura e da escrita: a exploração do velho para "ancorar o novo" e o uso de situações- problema que levem o aluno a recorrer às habilidades metacognitivas para solucioná-los. Segundo Ferreiro (1991), a aprendizagem da leitura e da escrita foi tradicionalmente considerada como um processo psicológico, um assunto de percepção de interpretação de símbolos gráficos. Nesta mesma direção, Kramer (1986), salienta que a escrita corresponde a uma construção de significados, afirmando que a prioridade pedagógica deve estar voltada para os usos sociais da língua escrita e não para exercícios visando à automatização ou memorização dos significantes. Esta é uma crítica ao uso meramente escolar que se faz da língua. Ferreiro (1991) lembra a importância de, ao aproximarmo-nos dos usos escolares da língua escrita, dentro desse processo, é útil ter em conta as perspectivas da investigação psicolingüística e social sobre a lectoescrita. A perspectiva psicopedagógica tende para a concepção de um sujeito que aprende, através de um processo complexo, porém único e bastante autônomo (quer dizer, independente da variedade dos métodos de ensino) a encontrar o sentido dos múltiplos exemplos da língua escrita que se lhe apresentam. Em contraste, a investigação psicopedagógica nos mostra a grande variedade histórica e social nas práticas que implicam a leitura e a escrita. Nessa perspectiva, a escrita cobra existência social, não como estrutura abstrata, mas através de múltiplas formas particulares e vinculada, de maneira regular, a processos sociais e a situações de interação social que lhe dão sentido. Para Orlandi (1998) a língua é "relação lingüístico- histórica, discursiva, estabelecida por sujeitos concretos em condições de produção específicas". Sob este ponto de vista não há, pois, correspondência direta entre as palavras e as coisas, a relação palavra- coisa é uma relação social e histórica. Ainda segundo Orlandi (1998) nem todos os sentidos, porém, podem ser produzidos, já que esses são limitados pela materialidade da linguagem. Entende-se, pois, que há leituras possíveis, sentidos possíveis para um texto escrito, o que torna a língua "um sistema de relações e de sentidos onde, a princípio todos os sentidos são possíveis, ao mesmo tempo que sua materialidade impede que o sentido seja qualquer um" (Orlandi, 1998. Os destaques desse trabalho de qualificação da formação docente que vem sendo feito evidenciam o quanto é imprescindível uma abordagem em leitura e escrita que foque $o$ desenvolvimento da pessoa do leitor/escritor na Graduação em Pedagogia, potencializando a interface entre a Pedagogia e Psicopedagogia.

\section{Referências}

Bolzan, D. (2014) Formação de professores no programa Brasil alfabetizado: reflexões iniciais. Políticas Educativas, Porto Alegre. $\mathrm{N}^{\circ} 2$, v. 7, 37-50.

Christofoli, M.C.P. (2002). A aprendizagem da língua escrita: construção dos processos de ler e de escrever. Tese de Doutorado. Faculdade de Educação, Pontifícia Universidade Católica do Rio Grande do Sul, Porto Alegre, Brasil.

Ferreiro, E. Reflexões sobre alfabetização. 1991. São Paulo: Ed. Cortez.

FREIRE, Paulo, SHOR, Ira. Medo e ousadia. 1986. O cotidiano do professor. Rio de Janeiro: Paz e Terra.

Herbertz, D \& Vitória, M.I.C. 2010. Refletindo as dimensões presentes nos diários de aula das professoras de educação infantil e anos iniciais do ensino fundamental. $\mathrm{N}^{\circ}$ 7, v.1, 37-44.

Hoffmann, J. 2008. Avaliar, respeitar primeiro, educar depois. Porto Alegre: Mediação.

Lajolo, M. 1999. Do Mundo da Leitura para a Leitura do Mundo. São Paulo: Ática.

Kato, M. 1986. No mundo da escrita: uma perspectiva psicolinguística. Editora Ática.

Orlandi, E. P. 1998. Interpretação: Autoria, leitura e efeitos do trabalho simbólico. Petrópolis: Vozes.

Marcelo Garcia, Carlos. 1999. Formação de Professores: para uma mudança educativa. Porto: Porto Editora.

Orlandi, E. P. 1995. Constantes y desafios actuales de la profesión docente. Revista de Educación. $N^{\circ} 306,205$ 242.

Mosquera, Juan \& Stobäus, Clauspucrs.br . 2006. Afetividade: a manifestação de sentimentos na educação. Educaão, Porto Alegre. $N^{\circ} 1,123-133$.

Sousa Santos, Boaventura de. 1987. Um discurso sobre a ciência. Porto: Afrontamento.

Sousa Santos, Boaventura de. 1994. Pela mão de Alice. O social e o político na pós-modernidade. Porto: Afrontamento.

Sousa Santos, Boaventura de. 2000. A crítica da razão indolente. Contra o desperdício da experiência. São Paulo: Cortez

Teberosky, A. [B] 1991. Los sistemas de escritura en el desarrollo delniño. Mexico: Siglo XXI.

Vygotsky, L. 1999. The zone of proximal development. Porto Alegre: Editora Ática.

Zabalza, Miguel. A. 2004. Diários de aula: um instrumento de pesquisa e desenvolvimento profissional. Tradução Ernani Rosa. Porto Alegre: Artmed. 